\title{
elyra
}

\section{Aproximações do cadáver esquisito à performance}

\author{
Danilo Bueno \\ Universidade de São Paulo
}

Resumo: Por meio de um cadáver esquisito escrito/jogado em Portugal, busca-se comparações desta técnica surrealista à performance, principalmente no que se refere às ideias de jogo coletivo e ritualístico, ao demonstrar as semelhanças na processualidade das duas operações, inclusive no tocante às alteridades.

Palavras-chave: Poesia portuguesa século XX, Cadáver esquisito, Performance, Surrealismo, Alteridade

Abstract: Through an exquisite corpse written/played in Portugal, this surrealist technique is compared with the performance, addressing, mainly, the ideas of collective and ritualistic game by demonstrating the similarities in the processuality of the two operations, including its alterities.

Keywords: Portuguese poetry twentieth century, Exquisite corpse, Performance, Surrealism, Alterity

1.

Escrever/Jogar um cadáver esquisito ${ }^{1}$ implica muitas variáveis, a partir desse jogo desenvolve-se a intuição, a adivinhação, o automatismo, o acaso e a coincidência, em uma produção imprevisível. Tais características geram uma condição cênica entre os participantes, colocando-os em situação, daí a tentativa de compreender esse procedimento surrealista também como performance, somada à visão libertária e mística dos propósitos da vanguarda francesa. $O$ ato coletivo da escrita torna-se o ponto ideal para se colocar em 
prática o vaticínio de Lautréamont, de que a poesia seria feita por todos, atacando frontalmente a autoridade do autor, esse pleonasmo que ratifica a centralidade do "eu". É justamente nesse ponto de contato que o atrito entre o impensado e o onírico constrói um ritual performático, ao possibilitar o cruzamento entre produção e público, criando-se uma rede de colaborações e recepções.

Nessa busca, pelo menos duas questões surgem: a primeira relaciona-se à definição de performance, conceito amplo e mutável, sujeito às diferentes épocas e teorias, que pode estar vinculada à atuação poética, visual, cinematográfica, pictórica etc. Desse modo, a noção de performance, aqui, permeia a própria circunstância de escrita do cadáver esquisito, para que se tenha uma abordagem que possa privilegiar uma leitura mais rente ao texto e às demandas cênicas de sua produção.

Já a segunda, talvez mais sutil, relaciona-se com o resultado do cadáver esquisito, na maioria dos casos, um poema impresso, que não indica, a não ser por meio de sua expressa denominação, a diferença processual em relação a um poema feito por apenas um poeta. Portanto, o que parece ser de interesse é a suposição do jogo performático desencadeado na criação, aquilo que não está escrito, mas apenas entrevisto, no acaso dirigido ${ }^{2}$ pelo gesto manifesto de se escrever um cadáver esquisito, criando-se uma tensão entre programação e desprogramação.

\section{2.}

Ao se pensar o cadáver esquisito sob a ótica da performance busca-se compreendê-lo por meio de um duplo trânsito: o poeta como criador e espectador (ou, ainda, no impasse criativo entre emissor e receptor), já que se torna criador no ato da escrita de seu verso(s) e espectador que não lê o(s) verso(s) alheio(s), sujeitando-se a um comprometimento com o vazio e com a espera. Nesse caso, o poeta que escreverá o verso, provavelmente, levará em consideração o espaço, o clima, o ambiente, a conversa prévia, as eventuais modulações do jogo, como regras restritivas ou parcelares, para, em um segundo momento, aceder ao lampejo preciso, que se quer automático e inconsciente, desprogramado de toda ordem para escrever/inscrever um verso. 
Esse caráter duplo da interatividade, entre observação do entorno e desprendimento mental, entre escrita e espera, faz com que esse procedimento seja, sobretudo, um compromisso entre duas ou mais subjetividades que se desconhecem para se encontrarem no gesto propiciado pelo acaso, de um verso escrito no escuro, anulando a predominância ególatra do autor que se vê circundado por variáveis fora de seu domínio, além de corroer o mito do gênio, em uma rede de socialização da escrita, por um lado, e pela fragmentação, por outro. Ensejaria, para melhor compreender todo o processo, "uma fenomenologia da recepção" (Zumthor 2010: 164).

Nessa linha de raciocínio, seria possível associar o cadáver esquisito com um movimento de alteridade bastante amplo que tangencia a compreensão de performance como abertura para o desejo, colocando-se a ação humana no limite entre o desconhecido e o prazer, em que os sonhos aparecem de forma concreta pela ação performática.

Assim, podemos ver a verdadeira natureza da performance: a do sonho, a de um processo onírico que supera a experiência imediata e envolve em suas brumas as ações concretas. Em suma, a performance é uma realização de desejos. Dessa forma, a performance não tenta fazer arte; é arte. (Glusberg 1987: 110)

Estabelece-se certa ligação entre o cadáver esquisito e a performance: a base formada por sonho/desejo que ambas as noções irão explorar, algo entre a submissão do ego aos processos do inconsciente, em uma abertura para o desconhecido, que é, no jogo (performance) uma constante relação com o outro, no improviso do presente a relação com o espectador sempre pronto a intervir na produção cênica. Assim, chega-se ao outro, pela via do desejo e do sonho, criando-se uma comunicação que almeja fluir como evento em comunidade.

Tal convergência assinala, além do ponto comum, um interesse semelhante alcançado por teorizações e vias diversas. Se o surrealismo buscou desde sempre o sonho como fuga da tirania da razão e a tentativa da exploração do inconsciente; a performance chegou ao mesmo ponto pela livre expressão do corpo, procurando intervir diretamente na recepção do espectador, buscando uma arte viva, diversa a cada apresentação, mimetizando a dinâmica da própria existência. É notório que durante as vanguardas europeias o germe de 
certa ideia de performance se alavancou (pelo menos as teorizações mais relevantes), talvez resultado da efervescência vanguardista em assombrar o público, integrá-lo ao campo de experimentação, diga-se, de indeterminação do espetáculo.

Não é de todo despropositado pensar-se certas técnicas surrealistas como meios para o choque e para a desautomatização do público, ainda vinculado a recitais e leituras de salão, em que a divisão artista/público estava bem marcada. Tanto a performance resolveu misturar esse "jogo de cena" dos recitais colocando o público na linha de frente do imprevisível, ao lado do corpo performático, quanto o cadáver esquisito propiciou que o participante fosse poeta e leitor, uma abordagem em comunidade.

Outro ponto de interesse seria o uso da improvisação como base para a criação artística: tanto o cadáver esquisito quanto a performance são únicos, são criados em determinado momento e dependem de fatores simultâneos e coletivos que não permitem uma reprodução seriada de suas atuações. São momentos que se exaurem, refratários ao arquivamento completo de suas intenções e inscrições. Como afirmar que o poema que resultou um cadáver esquisito presentifica toda a dinâmica entre os participantes? Nesse caso, parece que pontos significativos se esvaem, de modo a ler o resultado final muito mais como resto do monumento ao vazio criado pela troca de subjetividades atuantes na escrita.

Pode-se, então, afirmar que a performance e o cadáver negam e renegam a qualidade de produto, dada a natural instabilidade semântica da qual se revestem, ao objetar a reprodutibilidade técnica dos bens de consumo, não sendo circunscritos nem sistematizados por qualquer discurso. A base libertária dessas manifestações artísticas vem justamente dessa precariedade da fruição.

\section{3.}

A noção de alteridade a meio do caminho entre desprogramada e ritualizada, pode ser lida no cadáver esquisito abaixo, escrito pelo processo de "diálogo automático":

O diálogo em 1948

- O que é a família?

É o acto sexual praticado com um cadáver. 
- $O$ que é o surrealismo?

É a morte dos séculos projectando uma sombra muito longa debaixo da água do sonho.

$-O$ que é a loucura?

É a base de todas as paisagens.

- O que é o sonho?

É uma chamada obscurecida pelo recalcamento do desejo.

- O que é a pátria?

É uma coisa sem solução.

—És mulher?

Sim

- Porquê?

Porque é útil. (Cesariny (org.) 1989: 22)

Esse poema é precedido do seguinte paratexto: "O cadáver esquisito à beira-mar. Carlos Calvet, Mário Henrique Leiria. (Vivenda Maria Xavier. Carcavelos, 1948.)" (Cesariny (org.) 1989: 19). Mesmo com a indicação acima, não é possível saber se um poeta só perguntou e o outro só respondeu, nem se alternaram as perguntas e respostas ou se escreveram todas as perguntas e respostas antes e depois as cruzaram. Os procedimentos só podem ser supostos ou até certo ponto comparados com os diálogos automáticos efetuados por Breton.

O que parece significativo é o título: "O diálogo em 1948", que articula o encontro de dois poetas à beira mar para jogarem/escreverem uma conversação desarticulada que dá lugar para a congruência entre as duas subjetividades postas em um cenário comum, ou seja, como um acordo, entre ato e espaço, típico da performance (tempo, lugar e participantes ativam-se por um acordo coletivo, tácito ou não).

Duas perguntas são relevantes no que se refere ao perfil político dos poetas: sobre a família e sobre a pátria, dois pilares ideológicos do fascismo, período em que vigorava o regime salazarista ou Estado Novo (1933-1974), sabidamente um governo censor e torturador. As respostas às perguntas acima são precisas, no sentido de repudiar conjunturas teóricas fascistas: algo morto e algo sem solução, respectivamente. Observa-se, 
portanto, que apesar das regras do jogo vigorar às escuras, há a aproximação de um ponto de vista comum, o que apontaria para uma integração performática do acaso, mediada pelo substrato dos interesses comuns de ambos os escritores. Isso demonstra como o resultado do poema manufaturado depende de um contexto de surgimento que precisa ser resgatado como parte da rede de comunicação trazida pela troca comum, ainda mais no que tange a atuação dos escritores do cadáver/diálogo como burla da censura, em um gesto que seria um colóquio político transfigurado pela ação poética na livre agregação do pensamento e da subjetividade.

Do mesmo modo, quando o assunto gira em torno de valores positivos como o surrealismo, o sonho e a loucura, as respostas são igualmente reveladoras: o surrealismo "é uma sombra muito longa debaixo da água do sonho"; o sonho é uma chama pelo recalque do desejo e a loucura "é a base de todas as paisagens", atribuindo noções mágico/místicas da vivência renovada da prática surrealista. ${ }^{3}$

É perceptível como valores negativos e positivos são entremeados nas estrofes e ainda assim as respostas sugerem um acordo tácito da visão estrutural e política da literatura, fazendo com que essa processualidade sugira uma intervenção, provavelmente um dos propósitos mais distintos da performance e do Surrealismo. A ideia com que Mário Cesariny abre seu livro A intervenção surrealista parece demonstrar o teor político e ritual, melhor dizendo, um gesto político na medida em que é ritual:

Nenhum movimento como o surrealismo propôs tanto, a um só tempo, uma real cidadania para todos e uma real liberdade de cada um consigo. Síntese destinada aos maiores embates porque é dos tempos e da sua política não serem o tempo único em que a poesia se coloca, é no entanto, é sobretudo ela que dá maior gravidade à barca lançada por Breton rumo ao mar interior que move o homem (...) (Cesariny 1997: 09)

A visão do poeta português dialoga com a de Paul Zumthor sobre as relações entre performance e poesia oral, em uma frutífera sobreposição de ideias:

A poesia não mais se liga às categorias do fazer, mas às do processo: objeto a ser fabricado não basta mais, trata-se de suscitar um sujeito outro, externo, observando e julgando aquele que age aqui e agora. É por isso que a performance é também instância de simbolização: de integração de nossa 
relatividade corporal na harmonia cósmica significada pela voz; de integração da multiplicidade das trocas semânticas da unicidade de uma presença (...) (Zumthor 2010: 166)

Essas duas citações explicitam a dinâmica mais profunda do jogo ${ }^{4}$ : ao mesmo tempo em que o surrealismo busca "uma liberdade de cada um consigo", a processualidade da composição propicia a "integração de nossa relatividade corporal na harmonia cósmica". Essa aproximação denota o imbricamento entre automatismo e alteridade, sujeito às indefinições próprias do ato em si da performance.

Ao final, de forma ainda mais surpreendente, o debate sobre gênero aflora, em duas perguntas emparelhadas na mesma estrofe, talvez sugerindo uma união gráfica. Ser mulher porque é útil excede a simplicidade da resposta para captar uma sensibilidade homoerótica que é acima de tudo oposição ao conceito católico de família portuguesa daquela época, que funcionava como o núcleo menor da sociedade, e, por extensão, da pátria. Logo, uma oposição irrestrita aos ditames ditatoriais. A palavra Deus, que formaria o lema Deus/Pátria/Família - é silenciada no cadáver esquisito, talvez para ressoar o vazio de um mundo sem redenção divina. Além disso, ao valorizar a mulher em uma sociedade patriarcal, pode-se vislumbrar o viés antecipatório de questões atualíssimas sobre poesia e ética.

A relação entre os poetas é integral, fazendo com que ambos tenham uma vasta ligação de identidades, na alteridade processual do jogo, aproximando-os da fraternidade em ação.

\section{4.}

A poesia em voz alta, redimensionada a partir da ideia de performance, aponta para uma rica fatura intermidial, em que os elementos sonoros, visuais, cênicos, afinal, atualizamse na apresentação do poeta, em diálogo e contraste com algo além do poema impresso, uma articulação momentânea que considera o espaço, o público, os meios de propagação da voz (microfone, gravações, ecos), além das particularidades percebidas no exato momento da leitura performática, de forma intuitiva e improvisada, como no jazz, por exemplo.

Essa leitura, que alonga o poema escrito até entrelaçamentos inusitados, tem, em princípio, a finalidade de provocar um efeito intenso a ponto de proporcionar a apreensão do poético, em seu mistério de prazer e aprendizado, intensificando aquilo que poderia 
apenas ser lido silenciosamente por um fruidor errático, em uma biblioteca ou uma escola. Na leitura silenciosa, o que se evidencia é o leitor, ou ainda o fato dele estar centrado em si; já na proposta performática, a leitura é apenas um processo entre tantos outros, criando-se a diferença da leitura neutra e do leitor que experimenta outras percepções, em situação (cf. Zumthor 2007: 28).

O ritual é a própria presença genesíaca do verbo e de sua atualização, congregação entre performer e audiência. A religação proporcionada nesses momentos cria a dimensão catártica, espiritual, do encontro entre subjetividades poéticas.

Essas considerações sobre a performance poética e a leitura em voz alta, não valem completamente para o cadáver esquisito. ${ }^{5}$ Há um poema de aspecto comum (às vezes colagens ou desenhos) demarcado por um paratexto que indica local, data, participantes ou outras variáveis do processo. Porém, a ligação profunda entre os participantes do jogo torna-se apenas entrevista, como se a verdadeira performance fosse vedada ao fruidor do cadáver esquisito. Dessa forma, o leitor deve desdobrar do paratexto (ou seria melhor referilo como texto?) a situação precisa em que o cadáver esquisito teve lugar que seja recuperado cenografia e até mesmo a trilha sonora daquele poema, em uma tentativa de compreender o gesto mais profundo desse "jogo teatral", que comumente é encerrado com o desdobramento do papel e a leitura em voz alta do cadáver esquisito, ponto multiplicador de seu acontecimento, recuperando o poder encantatório da palavra/voz.

Nesse uso final, da leitura em voz alta, única parte do processo que pode ser repetida ao infinito, porém nunca de forma idêntica, dada a irrepetibilidade da voz, tem-se, ainda, um elo performático:

Por que Poesia/Performance?

Porque a ponte estabelecida com o público passa pela palavra que, na sua máxima expressividade gestual e musical, se faz gesto (sem deixar de ser palavra) e a Poesia volta para as pessoas a sua face mais ritual e festiva. (Branco 2001: 07)

Aliás, no que se refere ao cadáver esquisito, além de gesto, música e palavra, pode-se afirmar que ainda continua jogo, elemento que cruza alteridades face ao desconhecido. 


\title{
Notas
}

\begin{abstract}
${ }^{1}$ Nota referida sob a rubrica de "Léxico", ao final do livro Antologia do cadáver esquisito: "Jogo de papel dobrado que consiste em fazer compor uma frase ou um desenho por várias pessoas, sem que nenhuma delas possa aperceber-se da colaboração ou das colaborações precedentes. O exemplo, tornado clássico, que deu o nome ao jogo está contido na primeira frase obtida desse modo: 'O cadáver esquisito beberá o vinho novo'."
\end{abstract} (Cesariny 1989: 95). Ou ainda, uma definição que engloba a pintura: “(...) é o nome de um jogo coletivo surrealista, inventado na França, por volta de 1925, e divulgado por André Breton. Várias pessoas criam frases ou desenhos em um papel dobrado, de modo automático e sem saber o que os outros fazem. Abertas as dobras do papel surge um escrito compostos por fragmentos desconexos. Os surrealistas portugueses, na década de 1940, recuperaram o 'Cadáver esquisito' e outros jogos de automatismo e atividade coletiva, tanto nas artes plásticas como na literatura." (D’Horta 2012: 11, nota 3). Além disso, convém notar que hoje existem cadáveres esquisitos em vídeo, com danças comunitárias ou até mesmo letras de RAP feitas por essa técnica, que tem amplo uso nas mais variadas formas de produção cultural.

${ }^{2}$ O surgimento dessa expressão quer fazer coro com o conceito de "acaso objetivo" criado pelos surrealistas com apoio em Hegel: "segundo Hegel, é 'o lugar geométrico das coincidências'. Trata-se de um acúmulo de índices e coincidências que prefiguram um encontro amoroso ou fatal" (Rebouças 1986: 88). Desse modo, temse uma percepção que valorizava a comunicação errática e casual como meio para as descobertas e encontros mais inusitados.

3 "The only way to find adequate expression for this sur-realité is through an all-encompassing ethical commitment that the Surrealists refer to as 'the poetic life' ('la vie poétique) [...] Thus, far from a sideline occupation, the collective game practice [exquisite corpse] of the first generation of Surrealist in France is in fact the most distilled example of this 'poetic life'." (Kern 2009: 06-07)

${ }^{4}$ Poesia e jogo são quase indiscerníveis desde o princípio, conforme a visão de Johan Huizinga: “E, na realidade, a poiesis é uma função lúdica. Ela se exerce no interior da região lúdica do espírito, num mundo próprio para ela criada pelo espírito, na qual as coisas possuem uma fisionomia inteiramente diferente da que apresentam na 'vida comum', e estão ligadas por relações diferentes das da lógica e da causalidade." (Huizinga 2014: 133). E mais adiante “Em qualquer civilização viva e florescente, sobretudo nas culturas arcaicas, a poesia desempenha uma função vital que é social e litúrgica ao mesmo tempo. Toda a poesia da antiguidade é simultaneamente ritual, divertimento, arte, invenção de enigmas, doutrina, persuasão, feitiçaria, adivinhação, profecia e competição." (Idem: 134).

5 “Sujeito também, por vezes, a determinada fórmulas recuperadas, de uma vez mais, da tradição popular (como o que será, que será... das adivinhas) e que se torna o fio condutor do jogo, oferece em Portugal, como já o dissemos, uma riqueza e variedade maiores que, inclusive, os que podemos encontrar entre os próprios surrealistas franceses (e de tal pode dar conta, parcialmente, a antologia publicada por Cesariny)." (Cuadrado 
Danilo Bueno

1998: 53). Tal conceito, assim posto, recorda o cruzamento entre tradição popular/jogo/leitura, algo que pode ser associado à leitura em situação de Zumthor, criando nuances com um uso ancestral do automatismo enquanto procedimento necessário para vários jogos infantis. 


\section{Bibliografia}

Branco, Rosa Alice (2001), Em voz alta: poesia e performance, Porto, Campo das Letras.

Cesariny, Mário (1997), A intervenção surrealista, Lisboa, Assírio \& Alvim.

-- (org.) (1989), Antologia do cadáver esquisito, Lisboa, Assírio \& Alvim.

Cuadrado, Perfecto E. (org.) (1998), A única real tradição viva: antologia da poesia surrealista portuguesa, Lisboa, Assírio \& Alvim.

D’Horta, Vera. (2012), "LÁ e CÁ. Retrospectiva Fernando Lemos", Lá e Cá, Retrospectiva, Fernando Lemos, Pinacoteca do Estado de São Paulo, 09-15.

Glusberg, Jorge (1987), A arte da performance, São Paulo, Perspectiva.

Huizinga, Johan (2014), Homo ludens, São Paulo, Perspectiva.

Kern, Anne M. (2009), "From one exquisite corpse (in)to another: Influences and transformations from early to late surrealists games", in Kochhar-Lindgren, Kanta, Davis Schneiderman, Tom Denlinger Gusmão (orgs.) The exquisite corpse: chance and collaboration in surrealism's parlor game, Nebraska, Board of Regents of the University of Nebraska, 03-28.

Rebouças, Marilda de Vasconcelos (1986), Surrealismo, São Paulo, Editora Ática.

Zumthor, Paul (2010), Introdução à poesia oral, Belo Horizonte, Editora UFMG.

-- (2006), Performance, recepção, leitura, São Paulo, Cosacnaify.

Danilo Bueno é Doutor e Mestre em Letras pela Universidade de São Paulo (USP), pelo programa de Literatura Portuguesa. Interessa-se principalmente pela pesquisa de poesia portuguesa e brasileira dos séculos XX E XXI. Coordenou cursos livres de literatura e oficinas de criação poética no Centro Cultural São Paulo (CCSP), no Espaço Haroldo de Campos de Poesia e no SESC-SP. Integrou o grupo de estudos NELLPE - Núcleo de Estudos das Literaturas de Língua Portuguesa e Ética. 